how many disorders there are, or how many names there are for similar if not quite identical disorders. An overview by the editors would have been helpful, although not a substitute for firm editorial directives to the authors in the first instance. This, however, is a small quibble. The text offers an up-to-date authoritative account of the field that should be an excellent source of reference for some years to come.

\section{A Colour Atlas of Bone Disease}

By Victor Parsons. Pp. 112, illustrated. Wolfe Medical Publications, London, 1980. $£ 14.00$.

The main problem for anyone wanting to produce a book on bone disease for clinicians is that osteologists are not an identifiable species. The author, in a small book, has attempted to satisfy us all and, not surprisingly, has not succeeded. The inherent problem is compounded by a deliberate cmphasis on histology which, regrettable though it may be, most clinicians find a bore. Photomicrographs which are too small to show detail and have inadequate legends do not help. Unhappily the radiographic reproductions suffer the same fate. Added to this there are 2 chapters on History Taking and Examination, possibly aimed at medical students or postgraduate examination candidates, the illustrations of which are sometimes duplicated in the later chapters. There are 2 pictures of neurofibromatosis within a few pages of each other, and a number of other pictures such as a black and white one of a post-mortem pancreas, that are neither aesthetic nor instructive.

The text is tight and accurate but the illustrations, on which any atlas may depend, add remarkably little to it. Although most clinicians would get something of value out of the book it cannot be warmly recommended.

\section{The District Administrator in the National Health Service}

By Rosemary Stewart, Peter Smith, Jenny Blake and Pauline Wingate. Pp. 211. King Edward's Hospital Fund for London, London, 1980. £7.50.

This book records observations and comments, of 4 research workers, on the role, work and attitudes towards management of a selected number of district administratros and single district area administrators. An important reason for embarking on the research was to identify training needs, but it might be questioned whether this was achieved in sufficient depth. There are perhaps as many versions of the district administrator's job and responsibilities as there are district administrators, and any analysis should be in much greater detail, and recognize the interrelation between area activities (or lack of them) and the affairs of the district.

The chapter on training was tantalizing, for it could have said so much more than it did. The authors are quite right to emphasize the need for help in man management. This, however, needs considerable enlargement as the National Health Service is still remarkably confused as to who should do what and how one person should relate to another. The most important point made by the authors is that the district administrator should always be assessing the content and process of the service that he is providing. In other words, he should consciously aim to make certain that subordinates fill the gaps that his style of administration leaves. Not surprisingly, however, this begs the question of the elaborate selection process.

The various approaches a district administrator apparently has to his subordinates were identified as 'joining, supporting, monitoring, separate'. These concepts must be seen against the background of the demands, constraints and choices of the district administrator's job, all of which are carefully considered in this study.

One comment in the text is that the demand element is a comparatively small part of the job, with a wide variety of choices. This goes a long way to explaining the statement that most district administrators (some may think surprisingly) found that the satisfaction of the job outweighed the frustrations.

There are many fascinating observations in this book which should give rise to endless discussions, and a review cannot do justice to the various analyses of the district administrator's role in relation to the district management team, to other functions and to his own concept as a manager. Thought should seriously be given to the level of some of the district administrator's activities described, where actions were confused with those of a hospital secretary, or in some instances of a personal secretary or clerk. The book is completely specialist in nature and undoubtedly strives, almost too hard, to be objective. It is recommended to all who are involved in or wish to obtain a better understanding of Health Service administration at the district level.

\section{Essentials of Neurosurgery}

By Richard Hayward. Pp. 275, illustrated Blackwell Scientific Publications, Oxford, 1980. £9.75 (paperback). The book is a soft back, has 272 pages and is a useful size to be carried about; it is well classified and indexed and will be a useful reference for junior doctors. There are numerous illustrations, most of which are extremely helpful, but there are a few which are somewhat confusing. Although it contains all the essentials of the management of neurosurgical patients, the urgency with which certain forms of treatment should be administered is not sufficiently emphasized, particularly in the chapters on head injuries and spinal injuries, presumably this is corrected in Mr Hayward's book on the management of head injuries. He has summed up the present concepts in most topics and provides the reader with a clear outline of neurosurgical pathology and its management. The chapters on tumours and hydrocephalus are particularly well presented.

It is a book I would heartily recommend for house officers, accident and emergency room physicians, and useful reading for those preparing for postgraduate medical and surgical examinations. It will be marred for some by glaring spelling mistakes, which should have been eliminated during the preparation of the manuscript by the publishers of the book.

\section{Gynaecology by Ten Teachers}

Edited by S. G. Clayton, T. L. T. Lewis and G. Pinker. Pp. $x+385$, illustrated. Edward Arnold, London, 1980. $£ 10.75$.

Sixty years after the publication of the first edition, 'Ten Teachers' continues, despite changing contributors, to maintain the high standard which has come to be expected of it.

The reviewer has been impressed by the depth of coverage, the clarity of explanation and the topicality of content. Easy to read, frce of personal bias despite the multiple authorship and clearly set out, this book carries authority and must remain in the fore-front of student textbooks of gynaecology and can be unreservedly recommended.

\section{Holland and Brews Manual of Obstetrics}

By Robert Percival. 14th ed. Pp. xviii +876 , illustrated. English Language Book Society and Churchill Livingstone,

Edinburgh, 1980. $£ 20.00$ (low-priced edition $£ 6.00$ ).

First published in 1906, Holland's Manual of Obstetrics has now reached its 14th edition and has been thoroughly revised and partly re-written by Robert Percival and his collaborators.

New material in the current edition includes methods of study on fetal ecology, the use of ultrasound in obstetrics, the effects of medication on mother and fetus, the active 2. \title{
宛
}

